\title{
Avaliação em larga escala da educação básica e inclusão escolar: questões polarizadoras
}

Sandra Maria Zákia Lian Sousa*

\section{Resumo}

Com base na sistematização de aportes trazidos por pesquisas que tratam da avaliação em larga escala e externa, tal como tendencialmente conduzidas no Brasil, o artigo descreve características predominantes nas propostas implementadas e explora suas funcionalidades na concretização de padrốes de administração pública. Em particular, trata de implicaçóes de se associar incentivos aos resultados das avaliaçóes, na expectativa de que a avaliação gere competiçâo e a competição gere qualidade. São problematizados efeitos dessas iniciativas para a inclusão escolar, tema que, em última instância, nos remete à discussão da concretizaçáo do direito de todos a uma educação de qualidade. $\mathrm{Na}$ análise do potencial de exclusão escolar decorrente de usos dos resultados das avaliaçôes, são feitas referências específicas a alunos com deficiência matriculados em classes comuns da educação básica. As informaçôes analisadas evidenciam que esses estudantes, na maioria dos casos, são alijados da participaçáo nas provas, por meio de diferentes mecanismos. Conclui-se que o compromisso anunciado pelas diferentes esferas governamentais de que as avaliaçôes se constituem como mecanismo promotor da qualidade educacional tende a não acolher esse alunado que faz uso dos serviços de educação especial. Ademais, para esse acolhimento, tais avaliaçôes necessitam, em alguma medida, adaptaçôes, podendo, de algum modo, impactar o processo de inclusão escolar.

Palavras-chave: Avaliação em larga escala; Educação Especial; Inclusão Escolar.

* Professora doutora da Universidade de São Paulo (USP), São Paulo, São Paulo, Brasil. 


\section{Large-scale evaluation of basic education and school inclusion: polarizing issues}

\section{Abstract}

Based on the systematization of contributions brought by research that deals with large scale and external evaluation, as tendentially conducted in Brazil, the article describes predominant characteristics in the implemented proposals and explores its functionalities in the implementation of public administration. In particular, it addresses the implications of associating incentives with the results of evaluations, in the expectation that evaluation will generate competition and competition will generate quality. The effects of these initiatives are problematized for school inclusion, a topic that, in the last instance, refers us to the discussion of the realization of the right of everyone to a quality education. In the analysis of the potential for school exclusion resulting from the use of evaluation results, specific references are made to students with disabilities enrolled in common basic education classes. The information analyzed shows that these students, in most cases, are excluded from participating in the tests, through different mechanisms. It is concluded that the commitment announced by the different spheres of government, that evaluations constitute a mechanism that promotes educational quality, tends not to welcome the public of special education. In addition, for that reception, it needs adaptations, being able, in some way, to impact the process of school inclusion.

Keywords: Large-scale evaluation; Especial education; School inclusion.

\section{Evaluación a gran escala de la educación básica e inclusión escolar: cuestiones polarizadoras}

\section{Resumen}

En base a sistematización de los resultados de las investigaciones acerca de la evaluación a gran escala y externa, de acuerdo con la forma como han sido conducidas en Brasil, el artículo describe los rasgos predominantes en las propuestas implementadas y analiza sus funcionalidades en la concretización de estándares de la administración pública. En particular, el artículo trata de los efectos de se asociar incentivos a los resultados de las evaluaciones, con el propósito que la evaluación promueva la competición y esta resulte en calidad. Son problematizados los efectos de estas iniciativas a la inclusión escolar, temática que, en última instancia, se relaciona al debate de la concretización del derecho de todos a una educación de calidad. El análisis del potencial de exclusión escolar proveniente de los usos de los resultados de las evaluaciones son hechas referencias especificas a los estudiantes inscriptos en aulas comunes de educación básica. Las informaciones analizadas demuestran que estos estudiantes son, en general, impedidos de las participar las pruebas, a través de diferentes mecanismos. Se concluye que el compromiso anunciado por las diferentes esferas gubernamentales 
dice que las evaluaciones se constituyen como mecanismos que promueven la calidad educativa, sin embargo, no involucra el público de la educación especial. Además, para esa acogida, necesita adaptaciones, pudiendo, de algún modo impactar el proceso de inclusión escolar.

Palabras clave: Evaluación a gran escala; Educación especial; Inclusión escolar.

\section{Avaliação em larga escala da educação básica e inclusão escolar: questões polarizadoras}

Expressando uma agenda mundial, há quase três décadas avaliaçôes externas e em larga escala vêm sendo conduzidas como elemento central das políticas educacionais no Brasil. Dentre os argumentos de sustentação dessas propostas se destaca o reconhecimento ou a expectativa de que avaliaçóes dessa natureza têm potencial de incidir na qualidade da educação, tomando-se como principal evidência dessa qualidade o desempenho de alunos em testes cognitivos, como expressão de suas aprendizagens.

Desde então, estudos vêm sendo produzidos sobre avaliaçóes implementadas no país e trazem contribuiçóes sobre características dos delineamentos adotados, elucidam a utilização de seus resultados na condução das políticas educacionais e seus desdobramentos nas escolas e analisam sua funcionalidade para concretizar uma dada lógica de gestão do Estado. Com base na sistematização de aportes trazidos por esses estudos, o artigo trata de implicaçóes das iniciativas em curso para a concretização da inclusão escolar, tema que, em última instância, nos remete à discussão da concretização do direito de todos a uma educação de qualidade.

Para traçar características principais dos delineamentos das avaliaçóes externas e em larga escala da educação básica, implantados no Brasil pelo governo federal e por governos subnacionais, recorre-se à contribuições trazidas por pesquisas, particularmente aquelas que se distinguem por sua maior abrangência, que buscaram inventariar e sistematizar, com distintos graus de amplitude, um conjunto de experiências relativas às avaliaçôes, que se constituem em revisôes bibliográficas ou survey. Embora em menor número, se comparadas aos estudos que focalizam contextos locais, por meio de estudos de caso, pesquisas com este delineamento respondem ao intento de descrever atributos que têm se revelado dominantes nas propostas implantadas, sejam aquelas que se realizam sob a responsabilidade do governo federal, sejam as que se concretizam sob a decisão de estados e municípios.

Os elementos trazidos por meio da análise dessa produção subsidiam a discussão de implicaçôes da avaliação em larga escala para a inclusão escolar, em particular, de alunos com deficiência que fazem uso de serviços de educação especial.

Nessa perspectiva o texto apresenta, inicialmente, uma descrição sucinta do Sistema Nacional de Avaliação da Educação Básica (Saeb), de responsabilidade do governo federal e inclui referências a iniciativas de governos subnacionais. Aos elementos de caracterização, seguem-se consideraçôes que explicitam controvérsias suscitadas pelos usos que comumente são feitos de seus resultados, enquanto ins- 
trumentos de ação pública (LASCOUMES; LES GALÈS, 2012) que incidem na concretização do direito à educação. Em continuidade, são sistematizadas referências que ilustram peculiaridades da participação de alunos com deficiência em avaliaçóes em larga escala.

\section{Notas sobre iniciativas de Avaliação da Educação Básica vigentes no país}

O governo federal, por meio do Instituto Nacional de Estudos e Pesquisas Educacionais Anísio Teixeira (Inep), implementa o Sistema Nacional de Avaliação da Educação Básica (Saeb). Desde seu primeiro ciclo em $1990^{1}$, o Saeb passou por modificaçôes em seu escopo e metodologia. Freitas (2007) demarca duas fases distintas desde sua implantação, a primeira que previa mecanismos de colaboração e possibilidade de incorporação das avaliaçóes desenvolvidas pelos estados e governos locais, ao que se seguiu a centralização e federalização das açôes avaliativas voltadas para a educação básica”, perspectivas estas que apoiam análises de ordem técnica e política, que extrapolam os limites deste artigo.

O arcabouço hoje vigente tem suas bases na Portaria Ministerial no 931, de 21 de março de 2005 (BRASIL, 2005), que instituiu o Saeb, composto por dois processos avaliativos: a Avaliação Nacional da Educaçáo Básica (Aneb) e a Avaliação Nacional do Rendimento Escolar (Anresc). Em 2013, passou a incorporar também a Avaliação Nacional da Alfabetização (ANA), conforme dispõe a Portaria Ministerial no 482, de 7 de junho de 2013 (BRASIL, 2013) ${ }^{2}$.

A Aneb mantém as particularidades da avaliação da educação básica efetuada pelo Saeb até 2005. De periodicidade bianual, é realizada por meio de testes de desempenho em Língua Portuguesa - foco em leitura - e Matemática, em larga escala, externa aos sistemas de ensino e produz informaçóes por meio de amostras da população dos alunos do ensino fundamental e médio.

A Anresc, denominada Prova Brasil, mantém o escopo da Aneb, no entanto, é uma avaliação censitária, de larga escala, externa aos sistemas de ensino público, cujos resultados são divulgados por escolas.

A ANA é uma avaliação censitária, de larga escala, externa às redes públicas de ensino, aplicada anualmente no Ciclo de Alfabetização, com divulgaçáo de resultados por escola.

Estas avaliaçóes, embora se apresentem como direcionadas à avaliação da educaçáo básica, não contemplam a educação infantil - creches e pré-escola -, uma das etapas deste nível de ensino, como prevê a Lei de Diretrizes e Bases da Educação Nacional, de 1996. Superação de tal lacuna foi prevista por meio da Portaria Ministerial no 369, de 5 de maio de 2016 (BRASIL, 2016), que previa a formalização e inserçáo desta etapa no Sistema Nacional de Avaliação da Educaçáo Básica (Sinaeb). No entanto, a referida Portaria foi revogada poucos meses depois de sua publicação, 
pela Portaria no 981, de 25 de agosto de 2016, sob a alegação de que a instituição do Sinaeb deveria se dar após concluída a Base Nacional Comum Curricular (SOUSA, 2018).

Quanto ao Saeb, é oportuno ainda registrar que contempla, além dos testes, a aplicação de questionários contextuais, os quais se voltam ao levantamento de informaçôes de condiçôes intraescolares e extraescolares que incidem no processo de ensino e de aprendizagem, no entanto, o que tem tido tratamento, maior difusão e visibilidade pública são os resultados obtidos pelos alunos nos testes cognitivos.

Associado a iniciativas de avaliação, o governo federal, por meio do Inep, cria, em 2007, o Índice de Desenvolvimento da Educação Básica (Ideb), no âmbito do Plano de Desenvolvimento da Educação, para aquilatar a qualidade de ensino no território nacional. O Ideb é calculado a partir da taxa de rendimento escolar (aprovação) e das médias de desempenho nos exames padronizados, aplicados pelo Inep. Este Índice passa a se constituir em referência para a definiçáo de metas a serem alcançadas pelas redes públicas de ensino até $2021^{3}$.

O destaque ao Ideb, dentre as iniciativas do governo federal, deve-se ao fato de se ter evidências de que este teve um poder propulsor não só de maior atenção dos gestores aos resultados da Prova Brasil e ao fluxo escolar, mas também de ter induzido a ampliação de propostas de avaliação em âmbito de estados e municípios brasileiros (SOUSA, 2013).

O governo federal, sob a diretriz de imprimir qualidade à educação, difunde e legitima a ideia de monitoramento e avaliação, privilegiando as avaliaçôes externas e em larga escala de desempenho dos alunos como principal via para sua produção, além de induzir estados e municípios, náo só a se atentarem aos resultados das avaliaçóes nacionais, a criarem sistemas próprios, que tendem a reproduzir objetivos e procedimentos delineados pelas avaliaçóes nacionais.

Levantamentos recentes registram a existência de sistemas de avaliação estaduais em 23 unidades federadas e no Distrito Federal e a criação de Índices de Qualidade em dez desses estados (SOUSA, 2013; MACHADO; ALAVARSE; ARCAS, 2015; PERBONI, 2016; SOUSA; KOSLINSKI, 2017). Na Figura 1 é possível identificar as unidades com sistemas próprios de avaliação e aquelas que também instituíram Índices de Qualidade. 
Figura 1- Brasil, Existência de avaliaçôes em larga escala e índices de qualidade próprios em Unidades Federadas e Distrito Federal

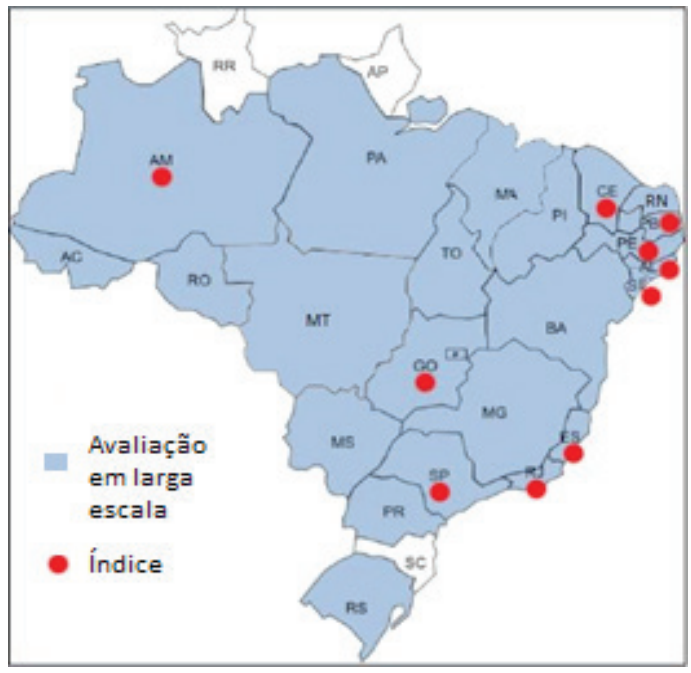

Fontes: Elaborado pelas Autora

Nos municípios também se constata a proliferação de sistemas próprios de avaliação em larga escala, o que foi evidenciado em estudo que se desenvolveu com abrangência nacional, por meio de survey (BAUER et al., 2016). Foram obtidas manifestações de 4.309 municípios do país (77,4\% do total). O mapeamento revelou tendência de adesão das municipalidades aos exames elaborados pelas instâncias federal e estadual, além de elaboração de propostas locais, como ilustra o seguinte registro:

Os municípios registraram] adesão às avaliações coordenadas pelo governo federal - com destaque para a Provinha Brasil ${ }^{5}$ (participaçáo de 97\% dos municípios), a Prova Brasil (participaçáo de $90 \%$ dos municípios) e a Avaliação Nacional da Alfabetização (participação de $90 \%$ dos municípios) —, 67\% dos municípios indicam compartilhar, também, das avaliaçóes externas implantadas pelos governos dos estados a que pertencem. A essa constatação soma-se a proposição de iniciativas de avaliação próprias pelos municípios, declaradas por $37 \%$ dos respondentes $(\mathrm{n}=1.573)$, o que representa cerca de $30 \%$ dos municípios brasileiros. Ainda, é oportuno registrar que $21 \%$ dos respondentes $(n=905)$ assinalaram pretender delinear uma proposta de avaliaçáo própria, o que corresponde a $16 \%$ do total de municípios do país. (BAUER et al., 2017, p. 5).

As sucintas referências às avaliaçóes em realização pelos governos federal, estaduais e municipais evidenciam que, gradualmente, se propagou o seu valor na esfera da formulação de políticas educacionais e se assimilou uma dada visão do que constitui o fazer avaliativo, resultando na coexistência e sobreposição de procedimentos, na medida em que os delineamentos assumidos tendem a apresentar propósitos e 
características semelhantes entre si, não se caracterizando por serem complementares, como evidenciam resultados dos estudos aqui referenciados. Como pondera Freitas (2007, p. 175):

\begin{abstract}
A regulação avaliativa centralizada teve repercussôes nas unidades federativas de natureza e com potencial formativo. As principais foram: a difusão de crenças e ideias relativas à avaliação em larga escala; a estimulação de sentimentos, atitudes e comportamentos favoráveis à prática dessa avaliação; a realização de aprendizagens concernentes à gestão educacional e à disciplina das relaçôes federativas no setor educação; e a disseminação de determinados valores.
\end{abstract}

Embora se reconheça "diferenças em relação à consistência técnica e operacional entre as diversas iniciativas em curso no país" (SOUSA, 2013, p.63), não se pode ignorar que seus resultados podem trazer informaçóes relevantes sobre a situação educacional, apoiando decisôes para enfrentamento de desafios diagnosticados. Estudos revelam que estas têm subsidiado açóes de diferentes naturezas, desde as que visam incidir no currículo e práticas pedagógicas, as que focalizam o monitoramento de rendimento dos alunos para proposição de atividades aos que apresentam dificuldades de aprendizagem e açóes para redução de repetência e evasão escolar, além de proposiçóes relativas à gestáo de escolas e de pessoal da rede (BROOKE; CUNHA, 2011; BAUER et al., 2016).

Contudo, essas açóes não necessariamente se colocam a serviço da inclusão escolar, entendida como compromisso com a realização do direito à educação para todos os alunos, com destaque para aqueles classificados na categoria deficiência. Não se pode desprezar o fato de que as avaliaçóes têm se constituído como uma das estratégias centrais de concretização de uma dada lógica de gestão da educação, que se pauta por controle de resultados, aos quais se associam consequências, muitas delas potencialmente capazes de contribuir para a seletividade e exclusão escolar.

\title{
Avaliações em larga escala e gestão educacional
}

No Brasil, como analisa Freitas (2007), desde os anos 1930 o Estado acolhe a avaliação como parte do planejamento educacional, no entanto, é nos anos finais da década de 1980 que esta é introduzida como ação sistemática no governo da educação básica.

As avaliaçóes externas e em larga escala da educação revelam-se como mecanismos que integram padróes de administração pública, que se ampliam e se fortalecem desde os anos 1980 (HOOD, 1991) e expressam aderência às tendências mundiais que vêm norteando iniciativas de diferentes países. Secchi (2009) caracteriza modelos organizacionais e relacionais inspiradores das recentes reformas da administração pública - o burocrático, a administração pública gerencial, o governo empreendedor e a governança pública - e realça que estes náo representam ruptura entre si, mas alinham-se na perspectiva de valores de eficiência, accountability e flexibilidade. 
O modo como estes princípios vêm sendo apropriados na gestão da educação pública tem sido objeto de análise em estudos relativos às avaliaçōes em larga escala, dado os formatos que gradualmente nelas se imprimem. Para uma retomada sucinta sobre a introduçáo e desenvolvimento da implantação da avaliaçáo em larga escala no Brasil, recorre-se ao artigo de Bonamino e Sousa (2012, p. 375), que caracteriza três geraçôes de avaliaçóes da Educação Básica. Como dizem as autoras, "ao tempo em que se sucedem, essas geraçóes coexistem no âmbito das redes de ensino; daí a necessidade de se tomar tal classificação como um recurso analítico".

A primeira geração, marcada pela criação do Saeb, apresenta a avaliação com caráter diagnóstico da qualidade da educação, que se volta a produzir informaçóes para monitorar e subsidiar decisóes de políticas educacionais. O delineamento assumido não comportava discriminaçáo de redes, escolas ou alunos.

A segunda geração se caracteriza por divulgar publicamente resultados das avaliaçôes por escola, sem estabelecer, no entanto, consequências materiais. A crença é a de que "o conhecimento dos resultados favorece a mobilizaçáo das equipes escolares para a melhoria da educação, bem como a pressão dos pais e da comunidade sobre a escola" (BONAMINO; SOUSA, 2012, p. 375), demandando seu aprimoramento.

Avaliaçóes de terceira geração relacionam resultados das avaliaçóes a consequências, para as escolas, seus profissionais e/ou alunos, ou seja, políticas de responsabilização forte ou high stakes, contemplando sançóes ou recompensas em decorrência dos resultados.

As iniciativas de terceira geração têm servido para apoiar novos modos de gestão educacional. Em textos anteriores, de nossa autoria e coautoria, se tomou esse debate como nuclear: Sousa, 1997; Mazzotta e Sousa, 2000; Oliveira e Sousa, 2003; Sousa, 2009; Sousa, 2014; Tripodi e Sousa, 2018. Pertinente mencionar dois artigos que versam sobre responsabilização e prestação de contas na avaliaçáo, publicados em 2013, que registram debate sobre políticas de accountability, estabelecido entre Brooke e Freitas, que põem em questáo os efeitos produzidos por estas políticas.

Frente aos limites deste artigo e considerando que ele integra dossiê que congrega trabalhos que tratam de avaliaçóes em larga escala na educação especial, a opção foi privilegiar, neste texto, a retomada de ponderaçóes feitas por Mazzotta e Sousa (2000) ao abordarem a temática da inclusão escolar e educação especial, no contexto da política educacional brasileira. Ao tratarem da reforma do Estado, os autores alertavam que ao se tomar o pressuposto ideológico de que o mercado é o agente principal de promoçáo de bem-estar social, restringe-se a noçáo de direitos sociais, dentre eles, direitos educacionais e, em consequência, produz-se um distanciamento com o compromisso da inclusão ou não segregação como norteador da educaçáo escolar. Comentam que a transposiçáo da lógica de gestâo privada para a educação pública,

[...] possibilita-nos compreender (não necessariamente aceitar) o papel nuclear que vem sendo atribuído, pelo poder público, à avaliaçáo, sendo esta entendida como instrumento capaz de informar sobre a eficiência e produtividade dos serviços educacionais, ou seja, indaga-se sobre os produtos educacionais e as condiçóes e 
custos de sua produção, ficando sem lugar as questóes relativas às finalidades e aos beneficiários dessa produção. (MAZZOTTA; SOUSA, 2000, p.104).

À época da escrita do referido ensaio, os autores aludiram que no Brasil, até aquele momento, na educação básica, não se vinha associando os resultados das avaliações a prêmios ou punições, no entanto, alertavam para essa possibilidade e suas consequências, tendo como parâmetro experiências de outros países. Com base em Whitty (1998, p. 106), são trazidos exemplos de efeitos da reforma educacional na Inglaterra e no País de Gales, dentre os quais a seleção, pelas escolas, de alunos com maior probabilidade de se saírem bem nos testes, mencionando-se que dentre "a clientela menos desejada pelas escolas encontram-se as crianças com necessidades educacionais especiais". Whitty registra em seu artigo:

[...] o prêmio atual pago por crianças portadoras de necessidades especiais pode náo ser suficiente, se fizer cair a procura pela escola por parte de clientes que, embora representem menos receita, trazem consigo outros atributos desejáveis. Bowe et al. (1992) e Vincent et al. (1995) dão exemplos de escolas que fazem exatamente este tipo de cálculo. (WHITTY, 1998, p. 201).

Na mesma perspectiva, é apresentada no ensaio citação de Afonso (1998, p. 124) que, ao explorar possíveis consequências da avaliação de sistemas educacionais, destaca que "as boas escolas estão desencorajadas de abrir as suas portas aos estudantes com necessidades educativas específicas [...]".

Dezoito anos se passaram desde que Mazzotta e Sousa fizeram esses alertas ao tratarem do tema da inclusão escolar e educação especial na política educacional brasileira, embora naquele momento as avaliaçôes implementadas se caracterizassem, majoritariamente, como de primeira geração. $\mathrm{Na}$ atualidade, em que vários estados e municípios já incorporaram como estratégia de ação pública a oferta de incentivos com base nas avaliaçôes em larga escala, sob a crença de que tal prática mobiliza as escolas, seus professores e alunos a buscarem melhores resultados, a problematização trazida pelos autores ganha relevo ao sair do campo das suposiçóes.

Subjacente a essa prática está a aceitação de resultados desiguais de alunos e escolas, resultando em prêmios para alguns e castigos para outros. A associação de incentivos aos resultados das avaliaçóes assenta-se na expectativa de que a avaliaçáo gere competição e a competição gere qualidade.

É legítima a expectativa de que a avaliação gere consequências. Vianna (2003, p. 53), ao tratar da validade das medidas educacionais, realça a validade consequencial, que se refere

[...] ao impacto da avaliação sobre o sistema, determinando mudanças de pensamento, gerando novos comportamentos, formando novas atitudes e promovendo novas açôes. A validade consequencial reflete em que medida a avaliação faz realmente alguma diferença para a comunidade.

O que se põe em questão é: 
- que consequências vêm sendo geradas ao se atrelar incentivos, simbólicos ou materiais, aos resultados das avaliaçóes em larga escala?

- esta é uma ação capaz de servir à concretizaçáo do direito à educação de qualidade para todos?

Sobre estas indagaçôes, já advertiam Mazzotta e Sousa (2000) que iniciativas dessa natureza incorporam a desigualdade e a exclusão como intrínsecos aos seus resultados, o que é incompatível com o direito de todos à educação e, portanto, não servem à inclusão escolar. A inclusão pressupóe que a escola se constitua em

$$
\begin{aligned}
& \text { [...] um espaço democrático e competente para trabalhar com to- } \\
& \text { dos os educandos, sem distinçáo de raça, classe, gênero ou carac- } \\
& \text { terísticas pessoais, baseando-se no princípio de que a diversidade } \\
& \text { deve não só ser aceita como desejada. (BRASIL, 2001, p.18). }
\end{aligned}
$$

Assumindo esta acepção de educaçáo inclusiva para o público alvo da educaçáo especial , com foco nos alunos com deficiência matriculados na rede regular da educação básica, a expectativa é que estes tenham garantido não só o direito ao acesso à escola, mas à permanência com aprendizagem.

A educação inclusiva, tal como concebida no documento que trata da política nacional de educação especial,

[...] constitui um paradigma educacional fundamentado na concepçáo de direitos humanos, que conjuga igualdade e diferença como valores indissociáveis, e que avança em relação à ideia de equidade formal ao contextualizar as circunstâncias históricas da produção da exclusão dentro e fora da escola. (BRASIL, 2008, p. 1).

Cabe indagar, nessa perspectiva, sobre efeitos da associação de incentivos aos resultados das avaliaçôes em larga escala aos alunos com deficiência que demandam serviços de educação especial.

\section{Alunos com deficiência e avaliações em larga escala}

$\mathrm{O}$ alerta quanto ao potencial de exclusão decorrente de usos dos resultados das avaliçôes, que gradualmente se imprimem nas políticas educacionais, ganha contornos específicos quando se trata do público-alvo da educação especial, matriculado na rede regular da educação básica.

A despeito do marco legal vigente no país, que assegura o direito à educação das pessoas com deficiência e do avanço no número de matrículas de crianças e jovens com deficiência em classes comuns da educaçáo básica (PRIETO; PAGNEZ, 2013), o que se evidencia, por meio de produçóes acadêmicas que tratam de avaliação em larga escala e educação especial, é um processo de exclusão. Antes mesmo que esses alunos venham a sofrer as consequências de iniciativas de uso classificatório e seletivo 
dos resultados das avaliaçôes, a sua participação nas avaliaçôes é previamente inviabilizada, desrespeitando orientação do Ministério da Educação / Secretaria de Educação Especial (Seesp) que trata de acessibilidade nos exames nacionais, asseverando que:

\begin{abstract}
Os órgãos federais, municipais e estaduais, ao aplicarem exames de avaliaçáo institucional ou de desempenho estudantil, devem assegurar as condiçóes necessárias para o pleno acesso e participação de estudantes com deficiência, considerando os princípios da acessibilidade e possibilitando, a todos, condiçóes de igualdade para a realizaçáo desses processos. [...] Tais recursos podem englobar desde a dilaçáo do tempo, até a disponibilização de recursos de tecnologia assistiva. $\mathrm{O}$ atendimento preferencial, assim como, a presença de profissionais intérpretes de $\operatorname{LIBRAS}^{6}$ e guia intérprete, devem ser previstos, para recepcionar e orientar os candidatos usuários de Libras, Libras tátil, alfabeto dactilológico tátil ou tadoma. (BRASIL, 2011, p. 107).
\end{abstract}

Tendo como base produções nacionais que abordam a participação desses estudantes nas avaliaçóes externas e em larga escala é possível evidenciar o quanto práticas vigentes em redes públicas de ensino e em escolas estão distantes dessas orientaçôes emanadas do Ministério da Educação.

Em estudo realizado em cinco municípios da Baixada Santista-SP, Monteiro (2010) analisou a participação na Prova Brasil de alunos com deficiência, matriculados no $5^{\circ}$ ano do ensino fundamental. Identificou, com base nas informaçôes obtidas, a presença de um discurso de que as avaliaçóes devem envolver todos os alunos, no entanto, constatou não haver igualdade de condiçóes de participação na Prova para pessoas com deficiência. Dentre outras mençôes, cita-se a orientaçáo emanada de uma secretaria municipal para que, no dia da prova, fossem aplicadas atividades diferenciadas para os alunos com deficiência, fora da sala de aula, caso esses alunos náo conseguissem realizar a prova.

Corradi (2011) buscou identificar fatores determinantes do desempenho de alunos surdos em Língua Portuguesa na Prova Brasil, matriculados em uma escola pública do estado do Paraná. Ao tempo em que realça a importância da participação desses alunos na Prova, constatou seu baixo desempenho, o que atribuiu, sobretudo, a ausência do intérprete de Libras durante a aplicação da prova.

Cardoso (2011, p. 34) focaliza suas análises na Política de Educação Especial de Sobral-CE, "com vistas a compreender como são desenvolvidos os processos de inclusão dos alunos com deficiência naquela municipalidade". Traz elementos sobre a participação do público-alvo da educação especial na Avaliação Externa de Sobral-CE e problematiza a inadequação desta avaliação e, também, da Prova Brasil para avaliar a aprendizagem desses alunos. Dentre suas conclusôes, no que se refere aos alunos com deficiência e avaliaçóes em larga escala, registra:

Analisando inicialmente o "lugar" dos alunos com deficiência na Avaliação Municipal de Sobral, em meio aos dispositivos de premiação, os identificamos como "as crianças da margem". A forma como participam esses alunos pode inspirar interpretaçôes diversas; a que sustentamos proporciona comparaçôes com histórias de "faz de conta". Os alunos com deficiência "fazem de conta" que são avaliados, e o sistema 
"faz de conta" que os avalia. O argumento que sustenta essa prática é ironicamente o da inclusão, contudo, consideramos que a iniciativa é das mais excludentes, em face da completa inadequaçáo dos instrumentos utilizados para os fins pretendidos. (CARDOSO, 2011, p. 225).

A autora registra o desafio de se desenvolver políticas de avaliação que superem a padronização, como condição para o acolhimento de todos os alunos com deficiência de uma rede de ensino.

Estudo de Silva e Meletti (2012) se voltou a analisar os índices de rendimento e frequência na Prova Brasil (2007) e Enem ${ }^{7}$ (2007) dos alunos com necessidades educacionais especiais ${ }^{8}$ atendidos na rede regular de ensino no município de Londrina-PR. Além de evidenciar a redução no número de matrículas no decorrer da educação básica, que indica a não permanência na escola desses alunos, em conclusão, as autoras registram sua baixa participaçáo nas avaliaçóes em larga escala, ou seja, o número de matrículas é superior ao número dos que realizaram as provas. Quanto a proficiência desses alunos nas provas, as autoras apresentam dados por tipo de deficiência, sendo, em geral, insatisfatórios os desempenhos apresentados. Em publicação posterior, Silva e Meletti (2012) incorporam dados de avaliaçôes em larga escala realizadas em 2018 e reiteram conclusóes do estudo anterior.

Raimundo (2013) analisou como vinha sendo a participação do público-alvo da educação especial na Prova São Paulo, entre o período de 2007 a 2011, avaliação externa e em larga escala criada pelo município de São Paulo. A autora assinala iniciativas que visam à inclusão deste público na avaliação, como a existência de aplicadores especiais (ledor, escriba e o guia-intérprete); adaptação de forma e aparência e adaptação de conteúdo, com ajustes no nível de dificuldade e nas habilidades para os alunos nas suas diferentes necessidades. Com base em depoimentos obtidos, é registrada no estudo a informação de que essas adaptaçôes não comprometem a validade dos resultados da avaliação em virtude da metodologia adotada. As adaptaçóes mencionadas, no entanto, não abarcam alunos com altas habilidades/superdotação, público este que integra o alunado elegível ao atendimento pela educação especial. Quanto à participação do público-alvo da educação especial na Prova São Paulo, a pesquisa registra que esta iniciativa tem gerado maior comprometimento dos profissionais da escola com a aprendizagem dos alunos.

Pesquisa de Witeze (2016) se voltou a analisar impacto da Prova Brasil na escolarização do público-alvo da educação especial em duas escolas estaduais da cidade de Goiânia. Com base nos resultados obtidos, a autora aponta a coexistência de processos de inclusão/exclusão inerentes ao Saeb e assinala

[...] tensôes e contradiçôes vividas pelos estabelecimentos investigados na compatibilização entre dois modelos distintos de avaliação e organização do trabalho pedagógico: o primeiro, fundamentado no reconhecimento da diversidade e na flexibilizaçáo dos conteúdos curriculares, dos recursos didáticos e das temporalidades; o segundo, ordenado a partir da homogeneização do desempenho dos alunos nos testes padronizados, numa perspectiva 
classificatória e mercadológica. (WITEZE, 2016, p.8).

As contribuiçóes das pesquisas aqui mencionadas, com exceção das referências feitas à prova organizada pelo município de São Paulo, trazem informaçóes que indicam tendência de alunos com deficiência, nem sempre de modo explícito, serem excluídos das avaliaçóes em larga escala, o que revela que, para estes alunos, as expectativas da escola se colocam em patamares distintos das relacionadas aos outros alunos. Se considerarmos a expectativa declarada nas propostas do governo federal, de governos estaduais e municipais de que essas avaliaçóes se constituem em mecanismo de promoção da qualidade da educação, pode-se afirmar que este compromisso tende a não acolher o público-alvo da educação especial.

Por outro lado, se nos pautarmos nos estudos que têm revelado as consequências de usos de resultados das avaliaçôes, náo se pode reivindicar a participaçáo desse alunado nas avaliaçóes externas e em larga escala sem as devidas adaptaçóes, o que certamente traria impactos no processo de inclusão escolar.

\section{Referências}

AFONSO, A. J. Políticas educativas e avaliaçáo educacional: para uma análise sociológica da reforma educativa em Portugal (1985-1995). Braga - Portugal: Universidade do Minho, 1998.

BAUER, A.; HORTA NETO, J. L.; PIMENTA, C. O.; SOUSA, S. Z.. Avaliaçáo e Gestáo Educacional em Municípios Brasileiros: mapeamento e caracterizaçáo de iniciativas em curso. Relatório Final. FUNDAÇÃO CARLOS CHAGAS; INSTITUTO NACIONAL DE ESTUDOS E PESQUISAS EDUCACIONAIS - ANÍSIO TEIXEIRA. São Paulo: FCC/INEP, 2016. (mimeo).

BAUER, A., SOUSA, S.Z., HORTA NETO, J. L. et al. Iniciativas de avaliação do ensino fundamental em municípios brasileiros: mapeamento e tendências. Revista Brasileira de Educaçáo, v. 22 n. 71, 2017.

BONAMINO, A.; SOUSA. S. Z. Três geraçôes de avaliaçăo da educação básica no Brasil: interfaces com o currículo da/na escola. Educação e Pesquisa, São Paulo, v. 38, n. 2, p. 373-388, abr./jun. 2012.

BRASIL. Ministério da Educaçáo. Instituto Nacional de Estudos e Pesquisas Educacionais Anísio Teixeira. Relatório SAEB (ANEB e ANRESC) 2005-2015: panorama da década. - Brasília: Instituto Nacional de Estudos e Pesquisas Educacionais Anísio Teixeira, 2018. 154 p.

BRASIL. Política nacional de educaçáo especial na perspectiva da educaçáo inclusiva. Brasília, 2008. Disponível em: <http://portal.mec.gov.br/arquivos/pdf/politicaeducespecial.pdf>. Acesso em: 07/05/2018.

BRASIL. Ministério da Educação. Diretrizes Nacionais para a Educação Especial na Educação Básica. Brasília, 2001. Disponível em: http://portal.mec.gov.br/seesp/arquivos/pdf/diretrizes.pdf. Acesso em: 07/05/2017.

BRASIL, Ministério da educação. Orientaçóes para implementaçáo da política de educaçáo especial na perspectiva da educaçáo inclusiva, 2015.

BRASIL. Nota Técnica no 08/2011, 2011. Disponível em: http://portal.mec.gov.br/index.php?option=com_docman\&view=download\&alias=17237-secadi-documento-subsidiario-2015\&Itemid=30192 Acesso em $14 / 05 / 2018$

BRASIL. Parecer CNE/CEB 17/2001, que dispõe as Diretrizes Nacionais para a Educação Especial na Educação Básica. 2001.

BROOKE, N.; CUNHA, M. A. de A. A avaliação externa como instrumento da gestão educacional nos estados. Estudos \& pesquisas educacionais, São Paulo: Fundação Victor Civita, 2011.

BROOKE, N. Controvérsias sobre políticas de alto impacto. Cadernos de Pesquisa. v.43 n.148. Sáo Paulo, p.336-347 jan./abr. 2013.

CARDOSO, A. P. L. B. Políticas de Educaçáo inclusiva em tempos de Ideb: escolarização de alunos com deficiência na rede de ensino de Sobral -CE. Dissertação, (Mestrado). 262f.Centro de Educação, Universidade Estadual do Ceará, Fortaleza, 2011. 
CARDOSO, A. P. L. B.; MAGALHAES, R. de C. B. P. Educação especial e avaliaçóes em larga escala no município de Sobral (CE). Revista de Educaçáo Especial, Santa Maria, v. 25, n. 44, p. 449-464, set./dez. 2012.

CARDOSO, A. P. L. B.; MAGALHAES, R. de C. B. P. Educação especial no contexto da política de avaliação em larga escala: a realidade de um município do nordeste brasileiro. In: Reuniāo Nacional da Anped, 36, 2013, Goiânia. Trabalhos. [S. 1.]: Anped, 2013.p. 1 - 15. Disponível em: <http://36reuniao.anped.org.br/pdfs/trabalhos_aprovados/gt15_trabalhos_pdfs/gt15_3319_texto.pdf>.

CORRADI, J. A. Avaliaçáo e desempenho de um aluno surdo na Prova Brasil: um estudo de caso. 2011. 69 f. Dissertação (Mestrado) - Curso de Educação, Faculdade de Educação, Universidade Estadual de Maringá, Maringá, 2011.

FREITAS, D. T. de. A avaliaçáo da educação básica no Brasil. Campinas: Autores Associados, 2007.

FREITAS, L. C. Políticas de responsabilização: entre a falta de evidência e a ética. Cadernos de Pesquisa. v.43 n.148. São Paulo, p.348-365 jan./abr. 2013.

HOOD, C. A public management for all seasons? Public Administration, v. 69, n. 1, p. 3-19, 1991.

LASCOUMES, P.; LE GALES, P. A ação pública abordada pelos seus instrumentos. Revista Pós Ciências Sociais, v.9, n.18, 2012.

MACHADO, C., ALAVARSE, O. M.; ARCAS, P. H. Sistemas estaduais de avaliação: interfaces com qualidade e gestão da educação. RBPAE, v. 31, n. 3, p. 667 - 680 set./dez. 2015.

MAZZOTTA, M. J. da S.; SOUSA, S. Z. Inclusão Escolar e Educação Especial: consideraçóes sobre a política educacional brasileira. Estilos da Clínica, Instituto de Psicologia da Universidade de São Paulo, v. 5, n. 9, p. 96-108, 2000.

MONTEIRO, K. R. A. Inclusáo escolar e avaliaçáo em larga escala: pessoas com deficiência na Prova Brasil. 122f. Dissertação (Mestrado). Universidade Católica de Santos, Santos, 2010.

TRIPODI, Z.F.; SOUSA, S. Z. Do Governo à Governança: Permeabilidade do Estado a Lógicas Privatizantes na Educação. CADERNOS DE PESQUISA (FUNDAÇÃ̉O CARLOS CHAGAS. IMPRESSO), v. 48, p. 228253, 2018.

PERBONI, F. Avaliaçóes externas e em larga escala nas redes de Educaçáo Básica dos estados brasileiros. Tese (Doutorado) - Faculdade de Ciências e Tecnologia, Universidade Estadual Paulista, Presidente Prudente, 2016.

PRIETO, R. G.; PAGNEZ, K. S. M. M. Direito à educação, educação especial e qualidade de ensino: indicadores e desafios para a área. MARTINS, Lucia de A. R.; PIRES, Gláucia N. da L.; PIRES, José. Caminhos para uma educaçáo inclusiva: políticas, práticas e apoios especializados. João Pessoa: Ideia, 2014. p. 49-83.

RAIMUNDO, E. A. Avaliação externa e educaçáo especial na rede municipal de ensino de São Paulo. 2013. 190 f. Dissertação (Mestrado em Educação) - Faculdade de Educação. Universidade de São Paulo, São Paulo, 2013.

SECCHI, L. Modelos organizacionais e reformas da administração pública. Rev. Adm. Pública, Abril, 2009, vol.43, n.2, p.347-369.

SILVA, M. C. V.; MELETTI, S. M. F. Avaliação em larga escala de alunos com necessidades educacionais especiais no município de Londrina (PR). Revista de Educaçáo Especial, Santa Maria, v. 25, n. 44, p. 417-434, set./dez. 2012.

SILVA, M. C. V.; MELETTI, S. M. F. Estudantes com necessidades educacionais especiais nas avaliaçốes em larga escala: Prova Brasil e Enem. Revista Brasileira de Educaçáo Especial, Marilia, v. 20, n. 1, p. 53-68, jan./ mar. 2014.

SOUSA, S.Z. Avaliação do rendimento escolar como instrumento de gestáo educacional. In: OLIVEIRA, D.A. (Org.). Gestão democrática da educação. Petrópolis: Vozes, 1997.

SOUSA, S.Z.; OLIVEIRA, R. P. de. Políticas de avaliação da educação e quase mercado no Brasil. Educ. Soc. 2003, vol.24, n.84, p. 873-895.

SOUSA, S. Z.; FREITAS, D. N. T. de. Políticas de avaliação e gestão educacional - Brasil, década de 1990 aos dias atuais. Educaçáo em Revista, Belo Horizonte, v 40, p. 165-186, dez. 2004.

SOUSA, S.M.Z.L. Avaliação e gestão da educaçáo básica no Brasil: da competiçáo aos incentivos. In: DOURADO, L. F. Políticas e gestão da educação no Brasil: novos marcos regulatórios? São Paulo: Xamã, 2009.

SOUSA, S. M. Z. L. Avaliação externa e em larga escala no âmbito do estado brasileiro: interface de experi-

Revista Educação Especial | v. 31 | n. 63 | p. 863-878 | out./dez. 2018

Santa Maria

Disponível em: <https://periodicos.ufsm.br/educacaoespecial> 
ências estaduais e municipais de avaliação da educação básica com iniciativas do governo federal. In: BAUER, A.; GATTI, B. A.; TAVARES, M. R. (Org.). Vinte e cinco anos de avaliaçáo de sistemas educacionais no Brasil: implicaçóes nas redes de ensino, no currículo e na formação de professores. Florianópolis: Insular, 2013. p. 61-87.

SOUSA, S.Z.; KOSLINSKI, M.C. Avaliação em larga escala, índices e premiação: iniciativas de estados brasileiros e seus efeitos. In: SETTON. M.G.J. Mérito, desigualdade e diferença: cenários da (in)justiça escolar Brasil e Portugal. São Paulo: Annablume, 2017.

SOUSA, S. Z. Avaliação da educação infantil: questóes controversas e suas implicaçôes educacionais e sociais. Rev. educ. PUC-Campinas, v. 23, n. 1, Campinas, 2018.

VIANNA, H. M. Avaliações nacionais em larga escala: análises e propostas. Estudos em Avaliação Educacional, n. 27, jan-jun/2003, p. 41-76.

WHITTY, G. (1998). Controle do currículo e quase mercados: a recente reforma educacional na Inglaterra e no País de Gales. In Warde, M. J. (org.). Novas políticas educacionais: críticas e perspectivas. São Paulo, SP: Pontifícia Universidade Católica de São Paulo, p. 193-209.

WITEZE, E. M. Processos de inclusáo/exclusáo escolar: análise do impacto da Prova Brasil na escolarização do público-alvo da educação especial. 277f. Universidade Federal de Goiás, Goiânia, 2016.

\section{Notas}

${ }^{1}$ Denominação inicial do Saeb foi Sistema de Avaliação do Ensino Público de $1^{\text {o }}$ Grau (Saep).

${ }^{2}$ Sobre o Saeb ver documento produzido pelo Inep (2018).

3 Disponível em: <http://portal.inep.gov.br/web/portal-ideb/como-o-ideb-ecalculado $>$. Acesso em: 10 out. 2015.

${ }^{4}$ A Provinha Brasil é composta de testes padronizados, de Língua Portuguesa e de Matemática, direcionados aos alunos da rede pública de ensino, matriculados no $2^{\circ}$ ano do ensino fundamental. A adesão a essa avaliação, pelas secretarias de educação das unidades federadas, é opcional, sendo sua aplicação submetida às decisões de cada secretaria. Disponível em: <http://portal.inep.gov.br/provinha-brasil-acesso >. Acesso em: 06 maio de 2018.

5 Público-alvo da educação especial, tal como definido na Política de Educação Especial na Perspectiva da Educação Inclusiva (BRASIL, 2008): pessoas com deficiência, transtornos globais do desenvolvimento e altas habilidades/superdotação. Lei 12.796 de 2013, incorpora essas categorias na LDB/96.

${ }^{6}$ Língua Brasileira de Sinais.

${ }^{7}$ Exame Nacional do Ensino Médio.

${ }^{8}$ Terminologia utilizada pelas autoras.

\section{Correspondência}

Sandra Maria Zákia Lian Sousa - Faculdade de Educação da Universidade de São Paulo, Av. da Universidade, 308. CEP:05508-040, Butantã, São Paulo, São Paulo.

E-mail: sanzakia@usp.br

Recebido em 16 de janeiro de 2018

Aprovado em 31 de setembro de 2018 


\section{(c) $(1)(9$}

This work is licensed under a Creative Commons Attribution-NonCommercial 4.0 International (CC BY-NC 4.0) 